\title{
17a-Ethynylestradiol and 4-Nonylphenol Stimulate Lung Adenocarcinoma Cells Production in Xenoestrogenic Way
}

Chia-Hung Sun ${ }^{1,2}$, Jou-Chun $\mathrm{Chou}^{3,4}$, Kuan-Po Chao

Hsian-Chi Chang ${ }^{5}$, Fu-Kong Lieu ${ }^{5}$, and Paulus S. Wang ${ }^{2,3,6,7, *}$

${ }^{1}$ Division of Chest Medicine, Department of Internal Medicine, Yang-Ming Branch, Taipei City Hospital, Taipei 11146

${ }^{2}$ Department and Institute of Physiology, School of Medicine, National Yang-Ming University, Taipei 11221

${ }^{3}$ Medical Center of Aging Research, China Medical University Hospital, Taichung 40402

${ }^{4}$ Department of Life Science, National Chung Hsing University, Taichung, 40227

${ }^{5}$ Department of Rehabilitation, Cheng Hsin General Hospital, Taipei 11212

${ }^{6}$ Department of Biotechnology, College of Health Science, Asia University, Taichung 41354

${ }^{7}$ Department of Medical Research, Taipei Veterans General Hospital, Taipei 11217,

Taiwan, ROC 
${ }^{*}$ Correspondence Authors: Dr. Paulus S. Wang

Institute of Physiology, School of Medicine, National Yang-Ming University,

Taipei 11221, Taiwan, ROC

Tel: $+886-2-2873-5558$

Fax: +886-2-2826-4049

Email: pswang3879@gmail.com

\section{Abstract}

Lung cancer has been the leading cause of cancer death in the world. In addition to smoking, estrogen is supposed to play an important role in the lung cancer development because women have a higher proportion of adenocarcinoma than men. In the environment, there are many metabolites and wastes that mimic human estrogen structurally and functionally. As an oral contraceptive, $17 \alpha$-ethynylestradiol (EE2) is released to wastewater after being utilized. Moreover, 4-nonylphenol (NP) exiting in the petrochemical products and air pollutants has estrogenic activity. In our study, 17ß-estradiol (E2), EE2, and NP are administered to stimulate A549 male lung adenocarcinoma cells and H1435 female lung adenocarcinoma cells. The results demonstrate that EE2 and NP stimulate A549 and H1435 cells proliferation in a dose- 
and time-dependent trend. Both estrogen receptor $\alpha$ and $\beta$ are activated simultaneously during these processes. Up-regulation of epidermal growth factor receptor (EGFR) and ERK expression is involved in response to estrogens. In conclusion, we first time report that EE2 and NP exert biotoxic effect to stimulate the proliferation of both male and female lung cancer cells in a dose- and time- response manner. New challenges from environmental hormones to lung cancer deserved further investigation.

Keyword: Lung cancer; Environment; EE2; NP; Estrogen receptor; EGFR.

Key Contribution: 17 $\alpha$-Ethynylestradiol and 4-Nonylphenol are environmental hormones which exert biotoxic effect to stimulate lung cancer proliferation. This study explores the potential impact of xenoestrogens on lung carcinogenesis.

\section{Introduction}

Lung cancer results in high mortality for decades worldwide. Although many

evidences have demonstrated the association between smoking and lung cancer incidence, there are still many female patients with lung cancer who never smoke [1]. Therefore, sexual difference is taken into consideration for carcinogenesis and 
estrogen is supposed to be a risk factor [2,3].

EE2 and NP are thought to be xenoestrogens because not only their molecular structures are close to $17 \beta$-estradiol and can bind estrogen receptor but also exert estrogenic function and lead to cellular response [4-9]. In recent years, these environmental hormones are discharged from wastewater, petrochemical products, and industrial fumes. Among the synthetic hormones, women generally take $17 \alpha$-ethynylestradiol (EE2) as oral contraceptive because its structure mimic natural estrogen 17ß-estradiol (E2) and has high efficacy [10]. EE2 is discharged from domestic sewage into wastewater treatment plants after being metabolized. As a consequence, the wastewater containing estrogenic compound is thought to be a major source flowing into the aquatic system. 4-Nonylphenol (NP), one of the final metabolites of nonylphenol polyethoxylate, is extensively made into detergents, pesticides, industrial chemicals, and vehicle fuel which are commonly seen around our life. With variable equivalent potency to E2 of these xenoestrogens, the occurrences in the environment are usually in higher concentration. The concentration of EE2 in wastewater was about $0.00-0.52 \mathrm{ng} / \mathrm{l}$ whereas NP was about $287-2058 \mathrm{ng} / 1$ $[7,11,12]$. Finally, people exposure to these contaminants by skin contact, drinking water, food intake, and inhaled gas. However, only limited information mentions about the potential lung carcinogenesis caused by environmental hormones $[6,13]$. 
Estrogen receptor (ER) $\alpha$ and $\beta$ are activated by estrogen and represent different biological response. It has been reported that estrogen stimulates the proliferation of human normal lung fibroblast cells and lung cancer cells [14]. As the concentration of estrogen increases, the ER $\beta$ activity increases which elicits lung cancer cell growth [15]. On the contrary, some authors bring up that ER $\alpha$ instead of ER $\beta$ is essential to affect the prognosis and survival of patients with lung cancer [16,17]. Either ER $\alpha$ or $\mathrm{ER} \beta$, the dominant role in lung cancer development after estrogen treatment is debatable.

The activation of epidermal growth factor receptor (EGFR) is regarded to be the key point to trigger the downstream signal transduction of mitogen-activated protein kinase/extracellular signal-regulated kinase (MAPK/ERK) pathway. Once ERK is phosphorylated, lung cancer will progress including cell proliferation, survival, angiogenesis, invasion, and metastasis [18,19]. Therefore, the tyrosine kinase inhibitor (TKI) of EGFR has been proved effectively in treating patients with lung adenocarcinoma [20].

Understanding the interaction between ER and EGFR in lung adenocarcinoma cells is based on the proliferative effect of estrogen and epidermal growth factor, alone or combined $[21,22]$. ER can be activated through estrogen dependent or independent pathway to promote lung cancer growth. However, there is still no 
sufficient evidence to clarify the relationship between ER and EGFR at the present time.

The aim of this study is to determine the proliferative effect of natural and environmental estrogens on lung adenocarcinoma cells. Considering the conflicting opinions associated with the pivotal operation responsible for lung cancer cells proliferation, the activities of both ER $\alpha$ and ER $\beta$ are measured at the same time. In order to figure out the interaction between ER and EGFR, the downstream signal transduction of MAPK/ERK pathway is also established.

\section{Results}

\subsection{Effects of 17ß-estradiol on the proliferation of MRC-5, A549, H1435, and}

\section{MCF-7 cells}

The cell proliferation tests were measured by MTT assay after exposure to E2. The effects of E2 on the proliferation of MRC-5 cells were showed in in Figure 1A. On day 3, higher concentration of E2 in $10^{-8}$ and $10^{-7} \mathrm{M}$ induced higher cell proliferation compared with vehicle $(p<0.05$ and $p<0.01)$. In Figure 1B, E2 promoted A549 cells proliferation in a dose- and time-dependent pattern. A maximum of 3.55-fold increase was observed in $10^{-7} \mathrm{M}$ of E2 on day 3 ( $\left.p<0.001\right)$. E2 also contributed to H1435 cells proliferation in a concentration-dependent trend (Figure 1C). The PI value of H1435 
cells reached a maximal 1.99-fold increase after exposure to $10^{-7} \mathrm{M}$ of E2 on day 2 $(p<0.005)$ MCF-7 cells were evaluated as a positive control. With higher concentration of E2 stimulation, the proliferation of MCF-7 cells was more significant (Figure 1D).

\subsection{Effects of $17 \alpha$-ethynylestradiol and 4-nonylphenol on the proliferation of} A549 and $\mathrm{H} 1435$ cells

A549 and H1435 cells were separately exposed to EE2 and NP to determine the proliferative effect by MTT assay. The effect of EE2 on the proliferation of A549 cells was shown in Figure 1E. On day 3, EE2 brought up to a maximal effect of 2.00-fold increase at $10^{-7} \mathrm{M}(p<0.01)$. In Figure 1F, EE2 also induced H1435 cells proliferation to a maximal value of 1.60 -fold increase in $10^{-7} \mathrm{M}$ on day $3(p<0.01)$. In Figure 1G, NP had the maximal influence of 2.73-fold increase in $10^{-7} \mathrm{M}$ on day 3 in A549 cells $(p<0.01)$. The maximal effect of NP on H1435 cell was in $10^{-7} \mathrm{M}$ on day2 $(p<0.05)$, and the values of PI was 1.20-fold increase (Figure 1H).

\subsection{Effects of 17ß-estradiol on the protein expression of ER $\alpha$, ERß, EGFR, and}

\section{p-ERK in lung adenocarcinoma cells}

We first time reported that both ER $\alpha$ and $\mathrm{ER} \beta$ were indeed detectable and 
simultaneously up-regulated in lung cancer cells by Western blot. In Figure 2A, the dose-response manner demonstrated that higher concentration of E2 resulted in higher intensity of both ER $\alpha$ and ER $\beta$ expressions in A549 cells. The maximal extents of ER $\alpha$ and ER $\beta$ were 1.50 -fold and 2.09-fold increase in $10^{-7} \mathrm{M}$ of E2, individually $(p<0.05$ and $p<0.01)$. The most significant expressions of EGFR and $\mathrm{p}$-ERK in A549 cells were shown in $10^{-7} \mathrm{M}$ of E2, individually.

In Figure 2B, ER $\alpha$ and ER $\beta$ were also co-expressed in H1435 cells, and revealed a concentration-dependent trend. The maximal extents of ER $\alpha$ and $\operatorname{ER} \beta$ were 1.62-fold and 1.63-fold increase in $10^{-7} \mathrm{M}$ of E2, individually ( $p<0.05$ and $p<0.05$ ). The up-regulation of EGFR expression in H1435 cells after exposure to E2 was most significant in $10^{-7} \mathrm{M}$ of E2. The maximal extent of p-ERK expression was evident in $10^{-9} \mathrm{M}(p<0.05)$ which decayed progressively afterwards.

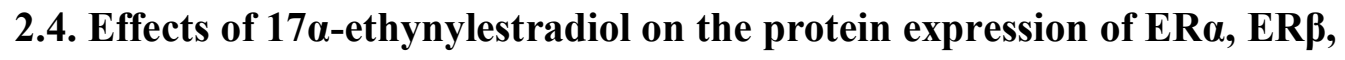

\section{EGFR, and p-ERK in lung adenocarcinoma cells}

In Figure 3A, synthetic oral contraceptive, EE2, was used to stimulate A549 cells.

Both ER $\alpha$ and ER $\beta$ were activated in $10^{-7} \mathrm{M}$ of EE2, and the maximal extent was

2.10-fold $(p<0.05)$ and 1.60-fold $(p<0.01)$ increase respectively. Similar to the condition of E2 exposure in A549, the expressions of EGFR and p-ERK were in a 
dose-response curve after EE2 challenge. The maximal extent of EGFR and p-ERK was expressed in $10^{-7} \mathrm{M}$.

Both ER $\alpha$ and ER $\beta$ in H1435 cells were co-expressed in a dose-dependent pattern after EE2 treatment in Figure 3B. The most obvious expression of ER $\alpha$ and ER $\beta$ were observed in $10^{-7} \mathrm{M}$ of EE2, and respectively reached to 1.41-fold $(p<0.05)$ and 1.69-fold $(p<0.05)$ increase. The most significant expression of EGFR was in $10^{-8} \mathrm{M}$ of EE2 and approached to 1.40-fold increase compared with control group $(p<0.05)$. The most distinct activity of p-ERK was found in $10^{-9} \mathrm{M}$ of EE2, and approached to 1.13 -fold increase $(p<0.05)$ which then decayed gradually.

\subsection{Effects of 4-nonylphenol on the protein expressions of ER $\alpha, E R \beta$, EGFR,}

\section{and p-ERK in lung adenocarcinoma cells}

To a lesser extent compared with E2, NP also showed xenoestrogenic activity on A549 cells in Figure 4A. The most apparent ER $\alpha$ expression was 1.28-fold increase in $10^{-7} \mathrm{M}(p<0.05)$ whereas ER $\beta$ expression was 1.22 -fold increase in $10^{-8} \mathrm{M}(p<0.01)$. The most meaningful expressions of EGFR and p-ERK were respectively in $10^{-7} \mathrm{M}$ and of $10^{-8} \mathrm{M} \mathrm{NP}$.

In Figure 4B, NP individually exerted 1.99-fold increase on ER $\alpha$ and 1.48-fold increase on ER $\beta$ in H1435 cells in $10^{-7} \mathrm{M}(p<0.05$ and $p<0.05)$. Though EGFR and 
p-ERK expression in H1435 cells were not so obvious than in A549 cells, the most distinguishable significance were individually observed in $10^{-7} \mathrm{M}$ and $10^{-8} \mathrm{M}$ of NP.

\subsection{The efficacy of natural and environmental estrogens}

In our study, the relative efficacy was to define the proliferative effect that other cell lines (A549, H1435, and MCF-7) can exert after E2 exposure compared with MRC-5 cells. In Table 2A, the fold-increase of proliferation in A549, H1435, and MCF-7 cells compared with MRC-5 cells after E2 stimulation was represented in different columns. A549 and H1435 cells had 2.41 times and 1.46 times of relative efficacy respectively.

The average efficacy was to define the proliferative effect of EE2 and NP compared with E2 on lung adenocarcinoma cells. A549 and H1435 cells were thought as control group, individually. In A549 cells, both EE2 and NP had 0.88 times of efficacy compared with E2 (Table 2B). In H1435 cells, EE2 had 1.14 times and NP had 1.07 times of efficacy compared with E2 (Table 2C).

\subsection{The activity of estrogen receptor after natural and environmental estrogens}

\section{stimulation}

The comparison of fold-increase of ER $\alpha$ and ER $\beta$ activity in A549 and H1435 cells 
after natural and environmental estrogens stimulation (Table 2D). The activities of ER $\alpha$ and ER $\beta$ activity in A549 and H1435 cells were diverse after E2, EE2, and NP stimulation.

\section{Discussion}

Lung cancer is a major health problem worldwide because it has become the leading cause of cancer death. According to previous epidemiology, the risk factors, incidence, choice of therapy, prognosis, and survival of females are different from that of males [1]. In this program, we focus on the effect of xenoestrogens on lung adenocarcinoma cells. By means of multiple exposure ways such as wastewater effluent, contaminated soil, detergents, plastic products, industrial chemicals, and vehicle exhaust, environmental hormones can be absorbed into skin, gastrointestinal tract, and respiratory system $[4,5,23]$. Since the natural toxins may impact the homeostasis of human body, the public concern has been raised. Because the types of xenoestrogen are complicated and the concentrations of xenoestrogen in the environment are variable, we try to qualify and quantify xenoestrogens exposure of human lung cancer cells in vitro. In our study, E2, EE2, and NP promote lung cancer cell proliferation in a dose- and time-response pattern. The results remind us not to neglect the potential impact of endogenous and exogenous estrogens on lung cancer 
development.

Many articles had proved the crucial role of estrogen in both normal lung development and cancer generation, and anti-estrogen inhibited this effect [24-26]. In our study, natural estrogen promoted normal lung fibroblast and adenocarcinoma cell proliferation. It meant that estrogen modulated early lung development and cancer growth because humans contacted with endogenous and exogenous estrogens from fetus to adulthood [25]. Immediate injury from estrogens was not observed in this in vitro experiment and could not completely apply to human complex organism. However, we should not look down on the influence of these potential ecotoxins on lung carcinogenesis. In Figure 1 and Table 2A, the relative efficacy of E2 in A549 cells was higher than that in H1435 cells (2.41 times and 1.16 times compared with MRC-5 cells). Our results revealed that once males with lung adenocarcinoma exposed to estrogen were more susceptible than females in vitro [27]. EE2 had a higher efficacy of 1.14 times in H1435 cells than 0.88 times in A549 cell (Table 2B and $2 \mathrm{C}$ ), and females were considered to be more liable to the harm of oral contraceptive than males [28]. In Table 2B and 2C, NP had a higher efficacy of 1.07 times in H1435 cells than 0.88 times in A549 cells which suggested that female lung cancer cells were more vulnerable than that of male. Despite lower potency, environmental estrogens exerted more intense bioactivity in high concentration $[7,11]$. 
Both ER $\alpha$ and ER $\beta$ were expressed in normal lung tissues and cancer cells though the distribution and activity were different in sex. Whether ER $\alpha$ or ER $\beta$ was more critical in regulating lung cancer growth, the authors did not have a common view $[14,16,17,29]$. In our experiment, ER $\alpha$ expression was relatively high in A549 than in H1435 cells while ER $\beta$ expression was relatively high in H1435 than in A549 cells (Figure 3 and Figure 4). In Table 2A, the fold-increase of ER $\alpha$ and ER $\beta$ activity was further compared after natural and environmental estrogens stimulated to determine which one had the major operation in lung cancer development. Either ER $\alpha$ or ER $\beta$ was higher than the other though the diversity was even found in the same cell line. Our data favored the predominance of ER $\beta$ in mediating E2-exposed lung cancer cells proliferation, but ER $\alpha$ also participated in this process [30]. This implied the difference of pathophysiology in lung carcinogenesis between male and female. Xenoestrogens mimic the structure and effect of natural estrogen. They bind with estrogen receptors and induce cellular response. EE2 and NP respectively also elicited different extent of ER $\alpha$ and ER $\beta$ in A549 and H1435 cells (Table 2D). The change of $\mathrm{ER} \alpha / \mathrm{ER} \beta$ balance might be related to the original property of xenoestrogens $[31,32]$.

The role of EGFR/ERK activation was ascertained in lung cancer advance which involved cell proliferation, migration, invasion, apoptosis, and metastasis [18,33]. ERK molecules underwent rapid phosphorylation upon EGFR activation, and decayed 
gradually thereafter. Our study revealed that this response even lasted longer for 3 days after estrogens exposure. These results suggested that EGFR/ERK pathways were continuously activated, and the downstream responses were proceeding.

Bidirectional signal transduction, genomic and non-genomic pathways, provided a rationale to explain the interaction between ER and EGFR [2,21]. After estrogen stimulation, ER $\alpha$ and ER $\beta$ in lung adenocarcinoma cells are simultaneously activated and hereby proceeds with ligand dependent and independent pathways. In ligand dependent pathway, estrogen binds with ER and form ER element. Then, ER-regulated genes are activated and induce downstream transcription. In ligand independent pathway, the trigger of ER leads to release and activation of EGFR. Especially associated with EGFR mutation and overexpression, ERK cascade is signaled and undergoes phosphorylation response. The transcription of target genes regulates the following cancer cell proliferation, invasion, angiogenesis, and metastasis. While ER inhibitor and EGFR TKI had anti-proliferative effects on lung cancer cells individually, the combined treatment enhanced these additional actions $[18,33]$. Dual target therapy indicates future promising value in clinical application. In conclusion, natural and environmental estrogens stimulate the development of both male and female lung cancer cells. We first time report that EE2 and NP provoke lung cancer cells proliferation in vitro in a dose- and time-dependent trend which is 
similar to that of E2. Both ER $\alpha$ and ER $\beta$ are simultaneously activated in lung adenocarcinoma cells and hereby up-regulate downstream EGFR/ERK pathways. Therefore, new approaches are deserved to discover the potential biotoxicity of environmental hormones in lung carcinogenesis in the future.

\section{Materials and Methods}

\subsection{Cell lines}

The human male normal lung fibroblast cell lines MRC-5, male lung cancer cell lines A549, and female breast cancer cell lines MCF-7 were obtained from Food Industry Research and Development Institute of Culture Collection and Research Center (Taiwan, ROC). The human female lung cancer cell lines H1435 was obtained from American Type Culture Collection (ATCC, NY, USA). A549 cells were cultured in Ham's F12K medium (Gibco Laboratories, Buffalo, NY, USA). H1435 cells were cultured in ACL-4 medium (Gibco Laboratories, Buffalo, NY, USA). MRC-5 and MCF-7 cells were cultured in Eagle's Minimum Essential Medium (MEM, Gibco Laboratories, Buffalo, NY, USA). All mediums were supplemented with 10\% fetal bovine serum (FBS, PAA Laboratories, Pasching, Austria), $2 \mathrm{mM}$ L-glutamine, Earle's BSS, $1.5 \mathrm{~g} / \mathrm{L}$ sodium bicarbonate, $0.1 \mathrm{mM}$ non-essential amino acids, $1.0 \mathrm{mM}$ sodium pyruvate, $50 \mathrm{IU} / \mathrm{mL}$ potassium penicillin $\mathrm{G}$, and $50 \mathrm{IU} / \mathrm{mL}$ 
streptomycin sulfate. All cells were maintained at $37^{\circ} \mathrm{C}$ in a humidified atmosphere containing $5 \% \mathrm{CO}_{2}$. The characteristics of each cell line were listed in Table 1A.

\subsection{Reagents}

The natural (E2) and environmental (EE2 and NP) estrogens were selected as target compounds and the characteristics were listed in Table 1B. E2, EE2, dimethyl sulfoxide (DMSO, as vehicle control), and 3-(4,5-dimethylthiazol-2-yl)-2,5diphenyltetrazolium bromide (MTT) were purchased from Sigma Chemical Co. (St. Louis, MO, USA). NP was purchased from Fluka (Buchs, Switzerland). Antibodies of ER $\alpha$ (D8H8), ERK, and p-ERK were purchased from Cell Signaling Technology (Beverly, MA, USA). Antibody of ER $\beta$ (N2C2) was purchased from Gene Tex (Irvine, CA, USA). Antibody of EGFR (1005) was purchased from Santa Cruz Biotechnology (Santa Cruz, CA, USA). Antibody of glyceraldehyde 3-phosphate dehydrogenase (GAPDH) was purchased from Thermo-Fisher Scientific (NY, USA).

\subsection{Cell Proliferation Assay}

Cell proliferation was determined by using modified colorimetric MTT assay.

Cells were grown on 96-well plates at a density of $2 \times 10^{4}$ cells per well and allowed to attach overnight. Then, they were challenged with different concentrations of E2, EE2, and NP (vehicle, $10^{-9} \mathrm{M}, 10^{-8} \mathrm{M}$, and $10^{-7} \mathrm{M}$ ) in each media containing $10 \%$ dextran coated charcoal-stripped FBS (DCC-FBS). The incubation time was 0, 1, 2, and 3 
days, respectively. The MTT assay was individually performed on day $0,1,2$, and 3 . The proliferation index (PI) of each day referred to the optical density (OD) of that day divided by the OD of day 0 . Each experiment was performed at least three times.

\subsection{Western Blot Analysis}

After incubation in different concentrations of E2, EE2, and NP (vehicle, $10^{-9} \mathrm{M}$, $10^{-8} \mathrm{M}$, and $10^{-7} \mathrm{M}$ ) for 3 days, the cells were harvested and lysed. Equal amounts of cell protein were electrophoresed on $10 \%$ sodium dodecyl sulfate (SDS)-polyvinylidene difluoride (PVDF) membrane (NEN Life Science Products, Boston, MA, USA) for immunoblotting. The primary antibodies of ER $\alpha, E R \beta, E G F R$, phospho-ERK, ERK, and GAPDH (internal control) following secondary antibodies were applied. Then, the proteins were visualized using enhanced chemiluminescence detection (Amersham International, Bucks, UK).

\subsection{Statistics}

All values were presented as the mean \pm SEM. Data were analyzed by Student's $t$-test between two groups and by one-way ANOVA followed by Duncan's multiple-range test. A $p$-value of $<0.05$ was considered to be statistically significant. Similar results were repeated at least 3 times.

\section{Acknowledgements}


This work was supported by grants from the scheduled research plan of Taipei City

Hospital, Taipei City Government, Taiwan (Grant 51-2013, 40-2015, 40-2016).

\section{Author Contributions}

Conceptualization, Chia-Hung Sun; Data curation, Jou-Chun Chou; Formal analysis,

Kuan-Po Chao; Project administration, Hsian-Chi Chang; Supervision, Fu-Kong Lieu;

Writing - review \& editing, Paulus S. Wang.

\section{Conflicts of Interest}

All authors declare no conflict of interest.

\section{References}

1. Wang, S.; Sun, T.; Sun, H.; Li, X.; Li, J.; Zheng, X.; Mallampati, S.; Sun, H.; Zhou, $X . ;$ Zhou, $C$., et al. Survival improvement in patients with non-small cell lung cancer between 1983 and 2012: Analysis of the surveillance, epidemiology, and end results database. Tumour Biol 2017, 39, 1010428317691677.

2. Levin, E.R. Bidirectional signaling between the estrogen receptor and the epidermal growth factor receptor. Mol Endocrinol 2003, 17, 309-317.

3. Hsu, L.H.; Liu, K.J.; Tsai, M.F.; Wu, C.R.; Feng, A.C.; Chu, N.M.; Kao, S.H. Estrogen adversely affects the prognosis of patients with lung adenocarcinoma. Cancer Sci 2015, 106, 51-59.

4. Fucic, A.; Gamulin, M.; Ferencic, Z.; Katic, J.; Krayer von Krauss, M.; Bartonova, A.; Merlo, D.F. Environmental exposure to xenoestrogens and oestrogen related cancers: Reproductive system, breast, lung, kidney, pancreas, and brain. Environmental Health 2012, 11, S8-S8.

5. Gong, Y.; Han, X.D. Effect of nonylphenol on steroidogenesis of rat leydig cells. Journal of environmental science and health. Part. B, Pesticides, food 
contaminants, and agricultural wastes 2006, 41, 705-715.

6. Kuo, L.C.; Cheng, L.C.; Lin, C.J.; Li, L.A. Dioxin and estrogen signaling in lung adenocarcinoma cells with different aryl hydrocarbon receptor/estrogen receptor alpha phenotypes. Am J Respir Cell Mol Biol 2013, 49, 1064-1073.

7. Ying, G.G.; Kookana, R.S.; Kumar, A.; Mortimer, M. Occurrence and implications of estrogens and xenoestrogens in sewage effluents and receiving waters from south east queensland. Sci Total Environ 2009, 407, 5147-5155.

8. Darbre, P.D. Chapter 3 - disrupters of estrogen action and synthesis. In Endocrine disruption and human health, Academic Press: Boston, 2015; pp 49-73.

9. Oyelowo, T. Chapter 2 - estrogen concepts. In Mosby's guide to women's health, Mosby: Saint Louis, 2007; pp 8-10.

10. Perez-Campos, E.F. Ethinylestradiol/dienogest in oral contraception. Drugs 2010, 70, 681-689.

11. De Mes, T.; Zeeman, G.; Lettinga, G. Occurrence and fate of estrone, $17 \beta$-estradiol and $17 \alpha$-ethynylestradiol in stps for domestic wastewater. Reviews in environmental science and bio/technology 2005, 4, 275.

12. Ying, G.G.; Williams, B.; Kookana, R. Environmental fate of alkylphenols and alkylphenol ethoxylates-a review. Environment International 2002, 28, 215-226.

13. Zhang, K.S.; Chen, H.Q.; Chen, Y.S.; Qiu, K.F.; Zheng, X.B.; Li, G.C.; Yang, H.D.; Wen, C.J. Bisphenol a stimulates human lung cancer cell migration via upregulation of matrix metalloproteinases by gper/egfr/erk1/2 signal pathway. Biomed Pharmacother 2014, 68, 1037-1043.

14. Stabile, L.P.; Davis, A.L.; Gubish, C.T.; Hopkins, T.M.; Luketich, J.D.; Christie, N.; Finkelstein, S.; Siegfried, J.M. Human non-small cell lung tumors and cells derived from normal lung express both estrogen receptor alpha and beta and show biological responses to estrogen. Cancer Res 2002, 62, 2141-2150.

15. Dougherty, S.M.; Mazhawidza, W.; Bohn, A.R.; Robinson, K.A.; Mattingly, K.A.; Blankenship, K.A.; Huff, M.O.; McGregor, W.G.; Klinge, C.M. Gender difference in the activity but not expression of estrogen receptors alpha and beta in human lung adenocarcinoma cells. Endocr Relat Cancer 2006, 13, 113-134.

16. Kawai, H.; Ishii, A.; Washiya, K.; Konno, T.; Kon, H.; Yamaya, C.; Ono, I.; Ogawa, J. Combined overexpression of egfr and estrogen receptor alpha correlates with a poor outcome in lung cancer. Anticancer research 2005, 25, 4693-4698.

17. Olivo-Marston, S.E.; Mechanic, L.E.; Mollerup, S.; Bowman, E.D.; Remaley, A.T.; Forman, M.R.; Skaug, V.; Zheng, Y.L.; Haugen, A.; Harris, C.C. Serum estrogen 
and tumor-positive estrogen receptor-alpha are strong prognostic classifiers of non-small-cell lung cancer survival in both men and women.

Carcinogenesis 2010, 31, 1778-1786.

18. Reddy, K.B.; Nabha, S.M.; Atanaskova, N. Role of map kinase in tumor progression and invasion. Cancer metastasis reviews 2003, 22, 395-403.

19. Xu, R.; Shen, H.; Guo, R.; Sun, J.; Gao, W.; Shu, Y. Combine therapy of gefitinib and fulvestrant enhances antitumor effects on nsclc cell lines with acquired resistance to gefitinib. Biomed Pharmacother 2012, 66, 384-389.

20. Krause, D.S.; Van Etten, R.A. Tyrosine kinases as targets for cancer therapy. The New England journal of medicine 2005, 353, 172-187.

21. Dubey, S.; Siegfried, J.M.; Traynor, A.M. Non-small-cell lung cancer and breast carcinoma: Chemotherapy and beyond. The Lancet Oncology 2006, 7, 416-424.

22. Ivanova, M.M.; Mazhawidza, W.; Dougherty, S.M.; Minna, J.D.; Klinge, C.M. Activity and intracellular location of estrogen receptors alpha and beta in human bronchial epithelial cells. Mol Cell Endocrinol 2009, 305, 12-21.

23. Aris, A.Z.; Shamsuddin, A.S.; Praveena, S.M. Occurrence of 17alpha-ethynylestradiol (ee2) in the environment and effect on exposed biota: A review. Environ Int 2014, 69, 104-119.

24. Hammoud, Z.; Tan, B.; Badve, S.; Bigsby, R.M. Estrogen promotes tumor progression in a genetically defined mouse model of lung adenocarcinoma. Endocr Relat Cancer 2008, 15, 475-483.

25. Patrone, C.; Cassel, T.N.; Pettersson, K.; Piao, Y.S.; Cheng, G.; Ciana, P.; Maggi, A.; Warner, M.; Gustafsson, J.A.; Nord, M. Regulation of postnatal lung development and homeostasis by estrogen receptor beta. Mol Cell Biol 2003, 23, 8542-8552.

26. Shen, H.; Yuan, Y.; Sun, J.; Gao, W.; Shu, Y.Q. Combined tamoxifen and gefitinib in non-small cell lung cancer shows antiproliferative effects. Biomed Pharmacother 2010, 64, 88-92.

27. Mollerup, S.; Jørgensen, K.; Berge, G.; Haugen, A. Expression of estrogen receptors $\alpha$ and $\beta$ in human lung tissue and cell lines. Lung Cancer 2002, 37, 153-159.

28. Baik, C.S.; Strauss, G.M.; Speizer, F.E.; Feskanich, D. Reproductive factors, hormone use, and risk for lung cancer in postmenopausal women, the nurses' health study. Cancer Epidemiol Biomarkers Prev 2010, 19, 2525-2533.

29. Raso, M.G.; Behrens, C.; Herynk, M.H.; Liu, S.; Prudkin, L.; Ozburn, N.C.; Woods, D.M.; Tang, X.; Mehran, R.J.; Moran, C., et al. Immunohistochemical expression of estrogen and progesterone receptors identifies a subset of 
nsclcs and correlates with egfr mutation. Clin Cancer Res 2009, 15, 5359-5368.

30. Mazieres, J.; Rouquette, I.; Lepage, B.; Milia, J.; Brouchet, L.; Guibert, N.; Beau-Faller, M.; Validire, P.; Hofman, P.; Fouret, P. Specificities of lung adenocarcinoma in women who have never smoked. J Thorac Oncol 2013, 8, 923-929.

31. Acconcia, F.; Fiocchetti, M.; Marino, M. Xenoestrogen regulation of er $\alpha /$ er $\beta$ balance in hormone-associated cancers. Molecular and Cellular Endocrinology 2016.

32. Nilsson, S.; Gustafsson, J.Å. Estrogen receptors: Therapies targeted to receptor subtypes. Clinical Pharmacology \& Therapeutics 2011, 89, 44-55.

33. Stabile, L.P.; Lyker, J.S.; Gubish, C.T.; Zhang, W.; Grandis, J.R.; Siegfried, J.M. Combined targeting of the estrogen receptor and the epidermal growth factor receptor in non-small cell lung cancer shows enhanced antiproliferative effects. Cancer Res 2005, 65, 1459-1470. 


\section{Figure legends}

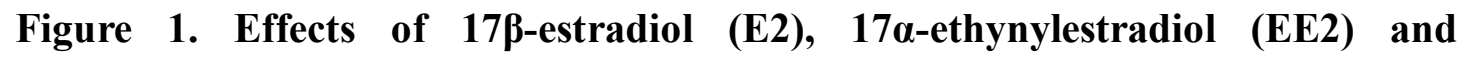
4-nonylphenol (NP) on the proliferation of MRC-5, A549, 1435, and MCF-7 cells. (A) MRC-5 male lung fibroblast cells with E2 stimulation (B) A549 male lung adenocarcinoma cells with E2 stimulation (C) H1435 female lung adenocarcinoma cells with E2 stimulation (D) MCF-7 female breast adenocarcinoma cells with E2 stimulation (E) A549 cells with EE2 stimulation (F) H1435 with EE2 stimulation (G) A549 cells with NP stimulation (H) H1435 with NP stimulation. Cell proliferation was measured by MTT assay after treatment with different concentrations of E2, EE2, and NP (vehicle, $10^{-9} \mathrm{M}, 10^{-8} \mathrm{M}$, and $10^{-7} \mathrm{M}$ ) for 3 days. The proliferation index was calculated by the OD value of each day divided by the OD value at day $0 .{ }^{*} p<0.05$, $* * p<0.01$, and $* * * p<0.001$ vs vehicle at each incubation time; $\mathrm{n}=4$.

Figure 2. Effects of 17ß-estradiol (E2) on the proteins expression of ER $\alpha$, ERß, EGFR, and p-ERK in A549 and H1435 lung adenocarcinoma cells. A549 and H1435 cells were treated with different concentrations of $17 \beta$-estradiol (vehicle, 10 $\mathrm{M}, 10^{-8} \mathrm{M}$, and $10^{-7} \mathrm{M}$ ) for 3 days. The collected cell proteins were analyzed and quantified by Western blot which represented as (A) Ratio of ER $\alpha / G A P D H$, ER $\beta / G A P D H, E G F R / G A P D H$, and p-ERK/ERK expression to vehicle in A549 cells. 


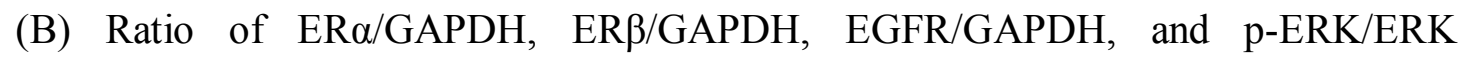
expression to vehicle in $\mathrm{H} 1435$ cells. ${ }^{*} p<0.05,{ }^{* *} p<0.01,{ }^{* * *} p<0.001$ vs vehicle at each concentration of $17 \beta$-estradiol; $\mathrm{n}=4$.

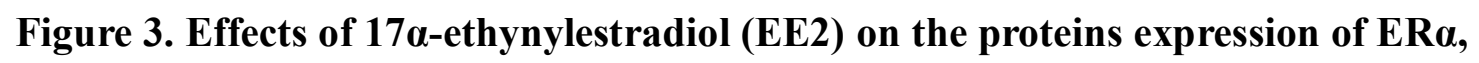
ERß, EGFR, and p-ERK in A549 and H1435 lung adenocarcinoma cells. A549 and H1435 cells were treated with different concentrations of $17 \alpha$-ethynylestradiol (vehicle, $10^{-9} \mathrm{M}, 10^{-8} \mathrm{M}$, and $10^{-7} \mathrm{M}$ ) for 3 days. The collected cell proteins were analyzed and quantified by Western blot which represented as (A) Ratio of ER $\alpha / G A P D H, E R \beta / G A P D H, E G F R / G A P D H$, and p-ERK/ERK expression to vehicle

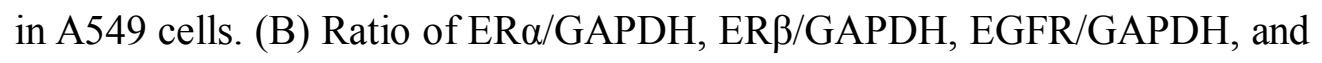
p-ERK/ERK expression to vehicle in H1435 cells. ${ }^{*} p<0.05$, ${ }^{*} p<0.01$ vs vehicle at each concentration of $17 \beta$-estradiol; $\mathrm{n}=5$.

Figure 4. Effects of 4-nonylphenol (NP) on the proteins expression of ERa, ERß, EGFR, and p-ERK in A549 and H1435 lung adenocarcinoma cells. A549 and H1435 cells were treated with different concentrations of 4-nonylphenol (vehicle, $10^{-9}$ $\mathrm{M}, 10^{-8} \mathrm{M}$, and $10^{-7} \mathrm{M}$ ) for 3 days. The collected cell proteins were analyzed and quantified by Western blot which represented as (A) Ratio of ER $\alpha / G A P D H$, 
ERß/GAPDH, EGFR/GAPDH, and p-ERK/ERK expression to vehicle in A549 cells.

(B) Ratio of ER $/ \mathrm{GAPDH}, \mathrm{ER} \beta / \mathrm{GAPDH}, \mathrm{EGFR} / \mathrm{GAPDH}$, and p-ERK/ERK expression to vehicle in $\mathrm{H} 1435$ cells. ${ }^{*} p<0.05,{ }^{*} p<0.01, * * * p<0.001$ vs vehicle at each concentration of $17 \beta$-estradiol; $\mathrm{n}=5$.

Figure 5. The efficacy and activity of natural and environmental estrogens. (A)

The relative efficacy of $17 \beta$-estradiol in A549, H1435, and MCF-7 cells compared with MRC-5 cells. (B) The average efficacy of EE2 and NP compared with E2 on A549 cells. (C) The average efficacy of EE2 and NP compared with E2 on H1435 cells. (D) The comparison of fold-increase of ER $\alpha$ and ER $\beta$ activity in A549 and H1435 cells after E2, EE2, and NP stimulation. E2: 17ß-estradiol; EE2:

17 $\alpha$-ethynylestradiol; NP: 4-nonylphenol. 


\section{Tables}

Table 1. The characteristics of cell line and estrogen in this study. (A) The characteristics of each cell line. (B) The characteristics of natural and environmental estrogen.

\begin{tabular}{|llll|} 
A & \multicolumn{3}{l|}{} \\
\hline Cell lines & Histology & Sex & Smoking status \\
\hline MRC-5 & Normal lung fibroblast & Male & Non-smoker \\
\hline A549 & Lung adenocarcinoma & Male & Unknown \\
\hline H1435 & Lung adenocarcinoma & Female & Non-smoker \\
\hline MCF-7 & Breast adenocarcinoma & Female & Unknown \\
\hline
\end{tabular}

B

\begin{tabular}{|c|c|c|c|c|c|}
\hline \multirow[t]{2}{*}{ Estrogens } & Molecular & Molecular & Sources & Relative & Structure \\
\hline & formula & $\begin{array}{l}\text { weight } \\
(\mathrm{g} / \mathrm{mol})\end{array}$ & & $\begin{array}{l}\text { potency to } \\
\text { E2 in vitro }\end{array}$ & \\
\hline $17 \beta$-estradiol (E2) & $\mathrm{C}_{18} \mathrm{H}_{24} \mathrm{O}_{2}$ & 272.38 & Human ovary & 1 & \\
\hline 17a-ethynylestradiol & $\mathrm{C}_{20} \mathrm{H}_{24} \mathrm{O}_{2}$ & 296.40 & Oral & 2 & \\
\hline (EE2) & & & contraceptives & & \\
\hline 4-nonylphenol (NP) & $\mathrm{C}_{15} \mathrm{H}_{24} \mathrm{O}$ & 220.35 & Petrochemical & 0.0001 & \\
\hline & & & products & & \\
\hline
\end{tabular}


Table 2. The efficacy and activity of natural and environmental estrogens. (A) The relative efficacy of $17 \beta$-estradiol in each cell lines. (B) The average efficacy of environmental estrogens compared with E2 on A549 cells. (C) The average efficacy of environmental estrogens compared with E2 on H1435 cells. (D) The comparison of fold-increase of ER $\alpha$ and ER $\beta$ activity in A549 and H1435 cells after natural and environmental estrogens stimulation. The relative and average efficacy were presented as mean \pm SEM.

A

\begin{tabular}{|lllll|}
\hline Estrogen & MRC-5 & A549 & H1435 & MCF-7 \\
\hline $17 \beta$-estradiol & $1 \pm 0.01$ & $2.41 \pm 0.09$ & $1.16 \pm 0.03$ & $1.56 \pm 0.05$ \\
\hline
\end{tabular}

B

\begin{tabular}{|ll|}
\hline Estrogens & Average efficacy to E2 in A549 cells \\
\hline $17 \beta$-estradiol (E2) & $1 \pm 0.01$ \\
\hline $17 \alpha$-ethynylestradiol (EE2) & $0.88 \pm 0.02$ \\
\hline 4-nonylphenol (NP) & $0.88 \pm 0.04$ \\
\hline
\end{tabular}




\begin{tabular}{|c|c|}
\hline Estrogens & Average efficacy to E2 in H1435 cells \\
\hline 17ß-estradiol (E2) & $1 \pm 0.01$ \\
\hline 17 $\alpha$-ethynylestradiol (EE2) & $1.14 \pm 0.09$ \\
\hline 4-nonylphenol (NP) & $1.07 \pm 0.10$ \\
\hline
\end{tabular}

D

\begin{tabular}{|lll|}
\hline Estrogens & A549 & H1435 \\
\hline $17 \beta$-estradiol (E2) & ER $\beta>$ ER $\alpha$ & ER $\beta>$ ER $\alpha$ \\
\hline $17 \alpha$-ethynylestradiol (EE2) & ER $\alpha>$ ER $\beta$ & ER $\beta>$ ER $\alpha$ \\
\hline 4-nonylphenol (NP) & ER $\alpha>$ ER $\beta$ & ER $\alpha>$ ER $\beta$ \\
\hline
\end{tabular}


Figure 1.
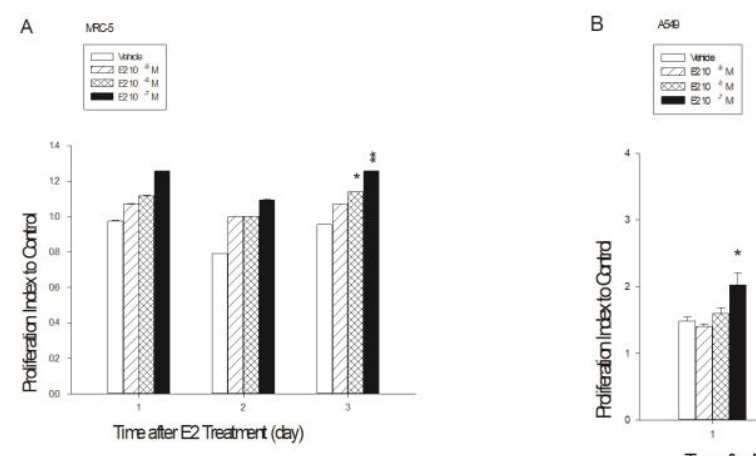

C hass

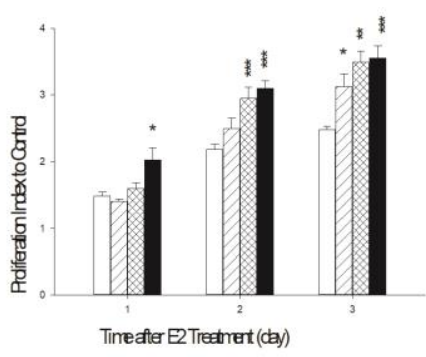

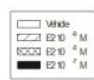

D
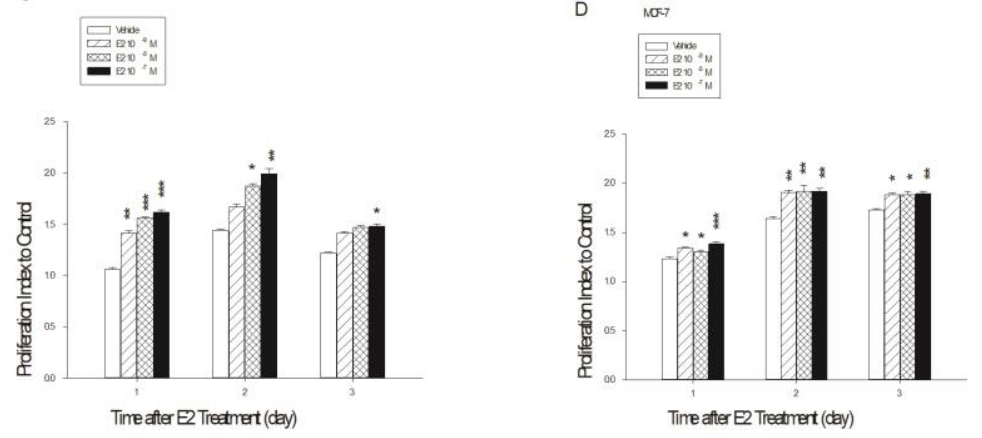

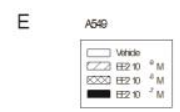

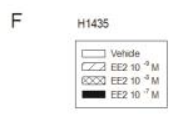
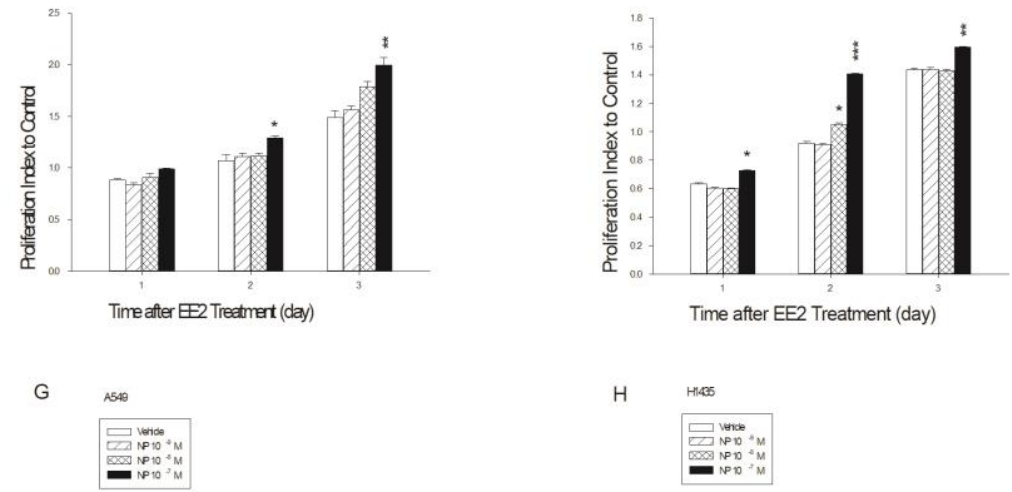

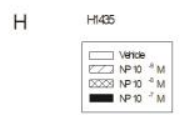
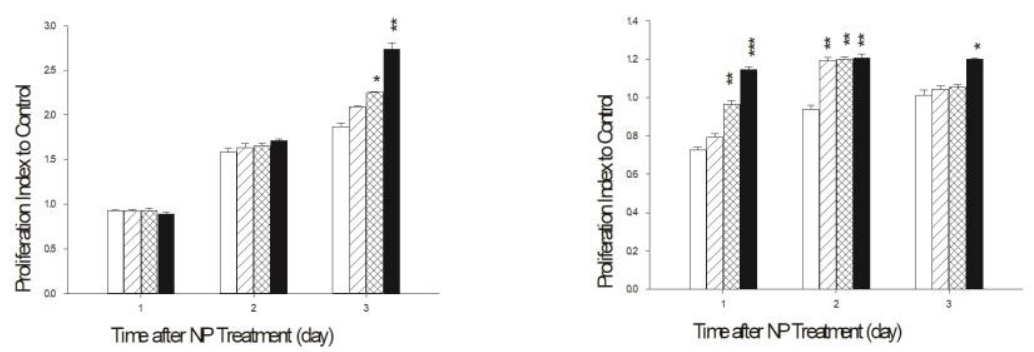
Figure 2.

A
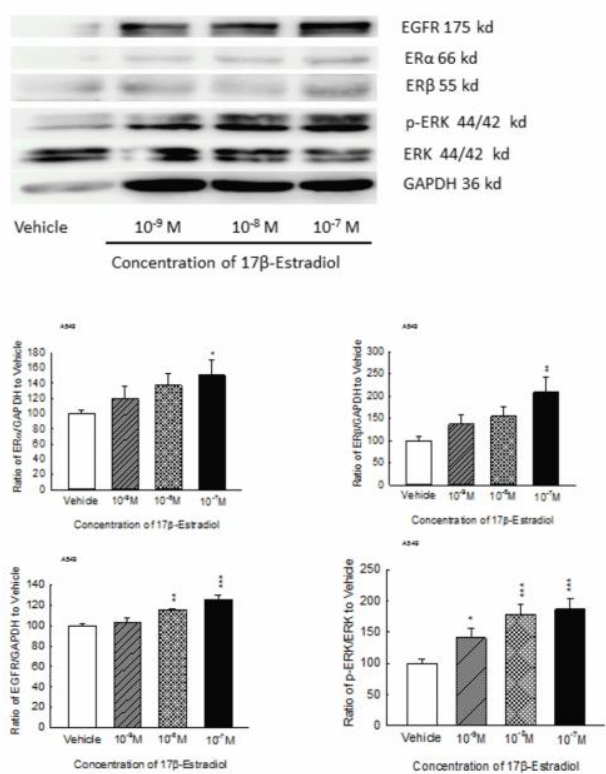

B
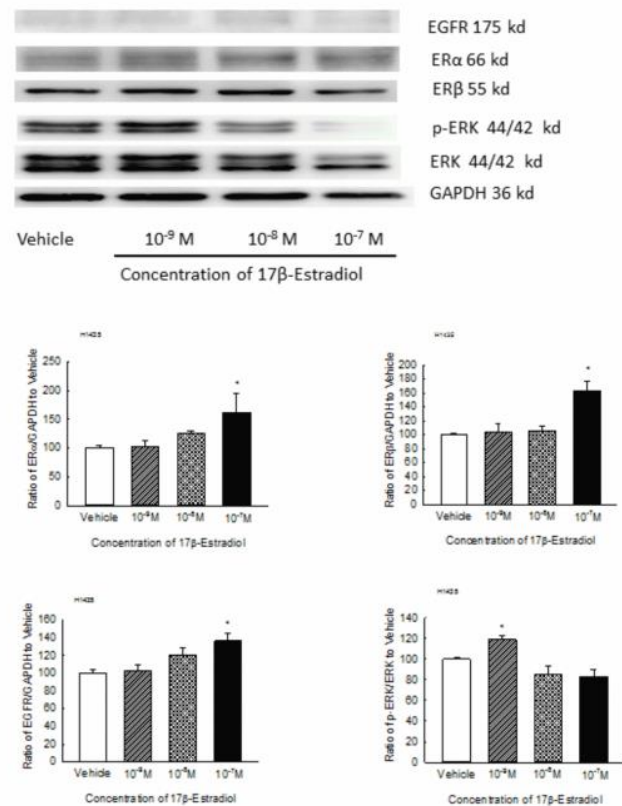
Figure 3.

A
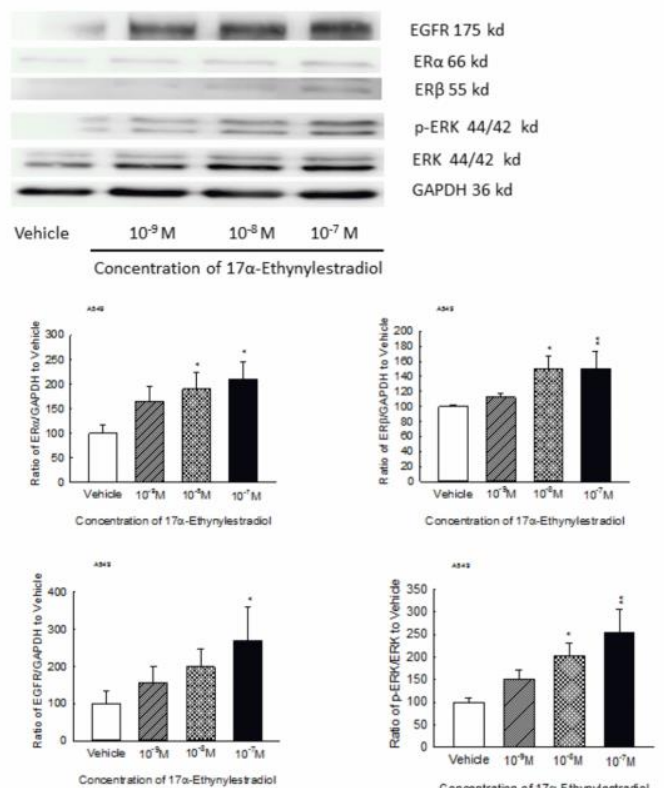

B

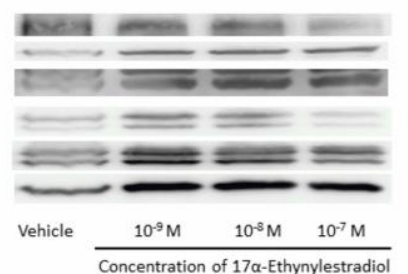

EGFR 175 kd

ERa $66 \mathrm{kd}$

ERB $55 \mathrm{kd}$

p-ERK $44 / 42 \mathrm{kd}$

ERK 44/42 kd

GAPDH $36 \mathrm{kd}$
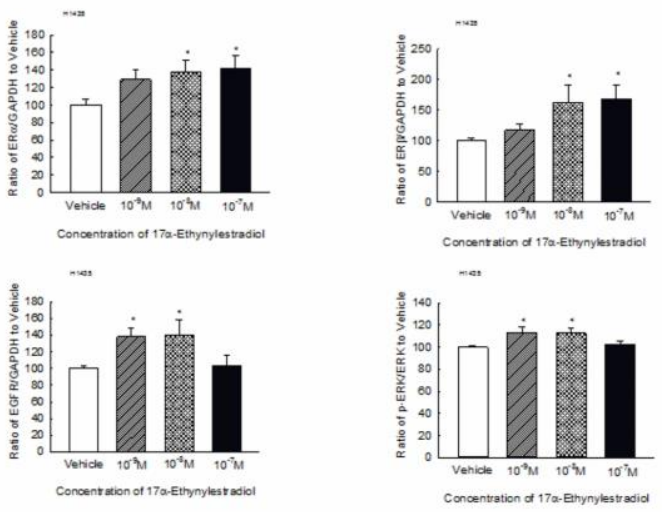
Figure 4.

A
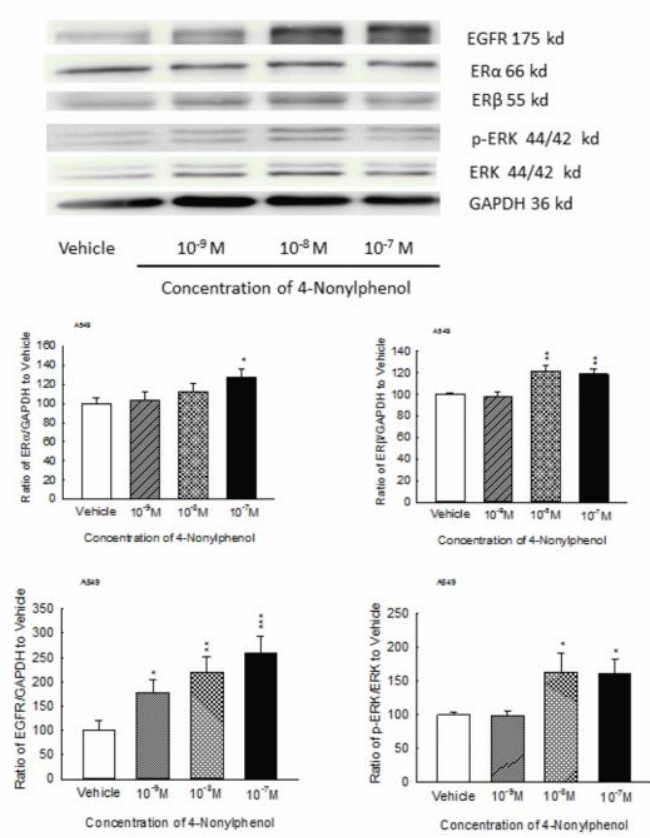

B
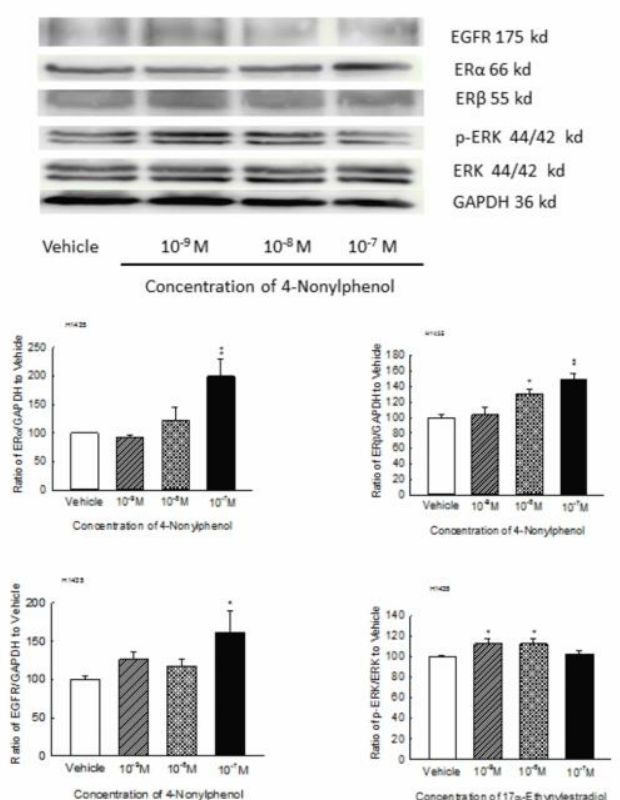